\title{
Special Interest Groups and the Australia-United States Free Trade Agreement
}

\author{
Lukas M. Weber* \\ School of Economics and Commerce \\ University of Western Australia
}

February 2006

\begin{abstract}
In the political economy model of Grossman and Helpman (1995), two incumbent governments attempt to negotiate a free trade agreement (FTA), while special interest groups in each country influence negotiations by offering financial contributions to their governments. As a consequence, a set of politically sensitive industries is excluded from the proposed FTA. Using the empirical methodology of Gawande, Sanguinetti, and Bohara (2001), this paper shows that the Grossman-Helpman (1995) model successfully predicts the set of excluded industries for the recently implemented Australia-United States FTA. It is also shown that the set of exclusions favours Australian interest groups, which could indicate that the gains from the FTA are lower for the government of Australia than for the government of the United States.
\end{abstract}

*Email: lukas@graduate.uwa.edu.au. This paper is based on a master's dissertation completed at the University of Western Australia, and was prepared with the assistance of an Honours/Master's Research Scholarship from the School of Economics and Commerce, University of Western Australia. I would like to thank my supervisor, Professor Kenneth W. Clements, for many valuable comments and suggestions. 


\section{Introduction}

Interest groups, also known as special interest groups or lobby groups, play a major role in the political processes of democracies. During election campaigns, for example, interest groups influence voting behaviour by issuing public endorsements of their preferred candidates, and by making financial contributions that candidates spend on advertising and other campaign activities. By issuing endorsements and financial contributions, an interest group can improve the electoral prospects of candidates that support the interest group's stance on key policy issues. This raises the expected welfare of members of the interest group, since it increases the likelihood that a future government will make policy decisions that are favourable to the interest group.

Endorsements and campaign contributions also benefit interest group members in another way. If electoral candidates are aware that interest groups will offer endorsements and contributions during the course of a campaign, then candidates will compete for the support of interest groups, which may result in candidates amending their policy announcements to suit the desires of certain interest groups. Therefore, interest groups have the power to directly influence the policy proposals of electoral candidates. This is true even if offers of endorsements and financial contributions are not made explicit, since their mere possibility may be enough to induce competition among candidates.

Incumbent governments can be influenced in the same way. Interest groups often publicly declare whether they support or oppose the policy proposals of incumbent governments, and interest groups routinely give campaign contributions even when there is no formal election campaign under way. Governments value this kind of support because public endorsements of policy can influence future voting behaviour, and financial contributions can be spent during 
future election campaigns or to provide immediate benefits such as improved party offices. Therefore, just like electoral candidates, incumbent governments seek to win the support of interest groups, which can be done by making adjustments to policy proposals.

The political economy approach to the analysis of policy formation explains these processes by viewing politicians and governments as rational agents, who maximise a welfare function that places value on their own welfare as well as on the welfare of voters. In an influential paper, Grossman and Helpman (1994) apply this approach to the analysis of international trade policy, constructing a model that predicts the schedule of import tariffs chosen by a government that is influenced by domestic interest groups. In Grossman and Helpman (1995), this model is extended to the international level to allow two countries to engage in negotiations for a free trade agreement (FTA). It is shown that FTA negotiations are usually more likely to succeed if a small number of industries can be excluded from the agreement, and for any two countries, the model predicts which industries are most likely to be excluded.

In this paper, the Grossman-Helpman (1995) model is applied to the Australia-United States FTA. The Australia-United States FTA came into force on 1 January 2005, after considerable debate and repeated rounds of negotiations by the two countries. A number of industries are excluded from the agreement, or subject to extended transition periods that effectively also constitute exclusions. Most of these exclusions are in agricultural industries, food/beverages/tobacco industries, and textiles/clothing/footwear industries. The aim of this paper is to test whether the Grossman-Helpman (1995) model can predict this set of excluded industries. This is done using the empirical methodology of Gawande, Sanguinetti, and Bohara (2001), who conduct a similar test for the Mercosur regional FTA. 


\section{Literature}

The literature on the political economy of trade policy attempts to explain why political processes often give rise to inefficient, protectionist trade policies. Rodrik (1995) and Helpman (1997) provide an overview of the major models that have been developed. Among these is the model of Grossman and Helpman (1994), which focuses on the influence of domestic interest groups over an incumbent government, and provides a solution for the equilibrium set of import tariffs. In this model, interest groups offer financial contributions to the government, with the amount of contributions by each interest group depending on the government's ultimate choice of tariff rate in the corresponding industry. The government chooses a set of tariff rates that maximises a welfare function, which depends on aggregate social welfare as well as the sum of financial contributions received from interest groups. ${ }^{1}$ This model has been empirically tested on a number of occasions. Goldberg and Maggi (1999) and Gawande and Bandyopadhyay (2000) find strong support using data for the United States, and McCalman (2004) finds supportive evidence using data for Australia.

Since its initial development, the Grossman-Helpman (1994) model has been extended in several ways. Feenstra (2004, Chapter 9) describes the major extensions. One extension is the model of Grossman and Helpman (1995), where two countries are allowed to enter into negotiations for a free trade agreement. ${ }^{2}$ In this extended model, each country's trade policy is determined by a two-stage strategic game. In the first stage, interest groups and the government interact at the domestic level, as described earlier in Grossman and Helpman (1994), while in the second stage, the two countries bargain at the international level in an

\footnotetext{
${ }^{1}$ Interest groups make financial contributions with the direct intention of influencing the government's policy choices, even though legislation frequently prohibits such behaviour.

${ }^{2}$ Levy (1997) investigates FTAs in the context of a different political economy model.
} 
attempt to negotiate an FTA. The model identifies conditions that increase the likelihood that these negotiations will succeed, and in particular, it is shown that a proposed FTA usually has a higher chance of success if a small number of politically sensitive industries are excluded from the agreement. For any two countries, the model also predicts the set of industries most likely to be excluded if an FTA is formed.

Gawande, Sanguinetti, and Bohara (2001) conduct an empirical test of the GrossmanHelpman (1995) model, using data for Argentina and Brazil. Together with their smaller neighbours Uruguay and Paraguay, these countries formed a regional FTA in 1995, known as Mercosur. Gawande, Sanguinetti, and Bohara find that the Grossman-Helpman (1995) model successfully predicts the set of excluded industries for this agreement. This paper uses the methodology of Gawande, Sanguinetti, and Bohara to test whether the Grossman-Helpman (1995) model can predict the set of excluded industries for the Australia-United States FTA.

\section{Theory}

\subsection{Interest Groups and Trade Policy}

A key result of the Grossman-Helpman (1994) model is an equation describing the equilibrium choice of trade tariffs and subsidies by an incumbent government, which receives financial contributions from domestic special interest groups. This result, which is derived below, holds for a single country that is not involved in any trade agreements with other countries. For each industry, the magnitude of the equilibrium tariff or subsidy effectively provides a ranking of the relative desirability, from the point of view of the government, of including that industry in a free trade agreement with the rest of the world. A modified form 
of this ranking is used later in this paper to investigate the choice of industry exclusions from the Australia-United States FTA.

The following derivation follows Goldberg and Maggi (1999) and McCalman (2004), who provide a slight simplification of the original Grossman-Helpman (1994) framework. The model assumes a small open economy, consisting of a continuum of individuals with identical preferences, and a population size equal to one. Individuals seek to maximise their utility, which is given by

$$
u=x_{0}+\sum_{i=1}^{n} u_{i}\left(x_{i}\right)
$$

where $x_{0}$ is consumption of good $0, x_{i}$ is consumption of good $i$, and the functions $u_{i}$ are increasing and concave. Good $i$ has domestic price $p_{i}$ and exogenous world price $p_{i}^{*}$, while good 0 acts as numeraire, with domestic and world prices both equal to one. Thus, an individual's demand for good $i$ is given by $x_{i}=d_{i}\left(p_{i}\right)$, where $d_{i}(\cdot)$ is the inverse of $u_{i}^{\prime}\left(x_{i}\right)$. For an individual with total expenditure $E$, indirect utility is then given by $V\left(p_{1} \ldots p_{n}, E\right)=E+\sum_{i=1}^{n} s_{i}\left(p_{i}\right)$, where $s_{i}\left(p_{i}\right)=u_{i}\left(d_{i}\left(p_{i}\right)\right)-p_{i} d_{i}\left(p_{i}\right)$ is the consumer surplus gained from each of the nonnumeraire goods.

Good 0 is produced using only labour, with constant returns to scale and an input-output coefficient equal to one, and therefore the wage rate is also equal to one. Each of the other $n$ goods is produced using labour and a sector-specific input. The return to the specific factor used in the production of good $i$ is given by the profit function $\pi_{i}\left(p_{i}\right)$, and the supply function for good $i$ is found using Hotelling's lemma, $y_{i}\left(p_{i}\right)=\pi_{i}^{\prime}\left(p_{i}\right)$. 
The government's policy options consist of trade taxes and subsidies. The domestic price of a good exceeds the exogenous world price if the government imposes an import tax or an export subsidy, and the domestic price is lower than the world price in the case of an import subsidy or an export tax. The government is assumed to redistribute tariff revenue equally among all voters, in the form of lump-sum payments.

Aggregate income, which is also equal to aggregate expenditure, is given by the sum of labour income, returns to specific factors, and tariff revenue. Aggregate welfare can therefore be found by summing indirect utility over all individuals and substituting for aggregate income:

$$
W=1+\sum_{i=1}^{n} \pi_{i}+\sum_{i=1}^{n}\left(p_{i}-p_{i}^{*}\right) m_{i}+\sum_{i=1}^{n} s_{i}
$$

where $m_{i}\left(p_{i}\right)=d_{i}\left(p_{i}\right)-y_{i}\left(p_{i}\right)$ represents imports of good $i$.

In some exogenous subset $L$ of the $n$ industries, the owners of the specific factors are assumed to form special interest groups. Each interest group offers the government financial incentives to choose trade policies that result in a high domestic price $p_{i}$ for the good produced by the corresponding industry. Individuals are too "small" to influence the government, so only interest groups make financial contributions. The total welfare of the interest group representing industry $i$ is equal to the sum of the indirect utilities of all individuals who belong to that interest group:

$$
W_{i}=\pi_{i}+\alpha_{i}\left(1+\sum_{j=1}^{n}\left(p_{j}-p_{j}^{*}\right) m_{j}+\sum_{j=1}^{n} s_{j}\right)
$$

where $\alpha_{i}$ is the fraction of the voting population that owns specific factor $i$, and each individual is assumed to own one unit of labour and at most one type of specific factor. 
The objective of interest group $i$ is to maximise its net welfare,

$$
W_{i}-C_{i}
$$

where the financial contributions paid to the government are represented by $C_{i}$, and these contributions depend on the trade policies chosen by the government.

The government's objective is to maximise a weighted sum of aggregate social welfare and total financial contributions received from interest groups. This can be represented by the following objective function:

$$
G=\sum_{i \in L} C_{i}+a W
$$

Aggregate social welfare is denoted by $W$, and $a$ is a measure of the government's valuation of aggregate welfare relative to financial contributions. The government values aggregate welfare because voters are assumed to be more likely to re-elect a government that has improved their standard of living, and the government values financial contributions because these can be spent during election campaigns to increase the chance of re-election.

To find the equilibrium trade policies, Grossman and Helpman (1994) use a "menu auction" framework. The approach used here is somewhat simpler, following Goldberg and Maggi (1999) and McCalman (2004). The interactions between the government and the interest groups are assumed to take the form of a Nash bargaining game. At the solution of this game, trade policies are chosen to maximise the joint surplus of the government and all interest groups. This joint surplus is given by 


$$
\begin{aligned}
\Omega & =\sum_{i \in L}\left(W_{i}-C_{i}\right)+G \\
& =\sum_{i=1}^{n}\left(a+I_{i}\right) \pi_{i}+\left(a+\alpha_{L}\right)\left(1+\sum_{i=1}^{n}\left(p_{i}-p_{i}^{*}\right) m_{i}+\sum_{i=1}^{n} s_{i}\right)
\end{aligned}
$$

where $\alpha_{L}=\sum_{i \in L} \alpha_{i}$ is the share of voters that are represented by interest groups, and $I_{i}$ is an indicator variable that equals one if $i \in L$ and zero otherwise. If $I_{i}$ is equal to one, industry $i$ is said to be "politically organised", since it is represented by an organised interest group.

The equilibrium tariffs and subsidies are then found from the first-order condition with respect to the domestic price of good $i$,

$$
\frac{\partial \Omega}{\partial p_{i}}=\left(a+I_{i}\right) \frac{\partial \pi_{i}}{\partial p_{i}}+\left(a+\alpha_{L}\right)\left(-d_{i}+\left(p_{i}-p_{i}^{*}\right) \frac{\partial m_{i}}{\partial p_{i}}+m_{i}\right)=0
$$

Applying Hotelling's lemma, and rearranging, this yields the final result:

$$
\frac{t_{i}}{1+t_{i}}=\frac{I_{i}-\alpha_{L}}{a+\alpha_{L}} \cdot \frac{z_{i}}{e_{i}}
$$

where $t_{i}=\left(p_{i}-p_{i}^{*}\right) / p_{i}^{*}$ is the ad valorem import tariff or export subsidy (positive), or import subsidy or export tax (negative) for good $i ; z_{i}=y_{i} / m_{i}$ is the ratio of domestic output to imports (or exports if $m_{i}$ is negative); and $e_{i}$ is the import demand elasticity (positive) or export supply elasticity (negative).

Equation (3) reveals the equilibrium trade policies that result from domestic political interactions between an incumbent government and various special interest groups. These trade policies particularly benefit industries that (i) are politically organised, (ii) have large absolute values of $z_{i}$, and (iii) have small absolute values of $e_{i}$. A large absolute value of $z_{i}$ 
indicates that the ratio of domestic output to imports or exports is high, so the economy has relatively little to lose from an import tariff or export subsidy, while the owners of the specific factor have much to gain. A small absolute value of $e_{i}$ means that the elasticity of import demand or export supply is low, in which case the deadweight loss associated with protection will also be low.

For each good $i$, the interest group representing the producers lobbies for positive protection, which would increase domestic prices. However, all other interest groups lobby for negative protection for good $i$, since the members of these other interest groups consume good $i$ but do not produce it. In the equilibrium, politically organised industries $\left(I_{i}=1\right)$ are usually given positive protection (import tariffs or export subsidies), and unorganised industries $\left(I_{i}=0\right)$ experience negative protection (import subsidies or export taxes).

Two notable special cases exist. Firstly, if all voters belong to interest groups $\left(\alpha_{L}=1\right)$ and all industries are politically organised ( $I_{i}=1$ for all $i$ ), then the competing demands of interest groups neutralise each other, and the equilibrium is free trade in all goods. Secondly, if only a negligible fraction of voters belongs to interest groups $\left(\alpha_{L}=0\right)$, then interest groups have nothing to gain from lobbying for negative protection for goods that their members consume. Therefore, interest groups lobby only for positive protection for the goods that their members produce, and in the equilibrium, only politically organised industries experience any trade taxes or subsidies.

When $\alpha_{L}=0$, the solution for the equilibrium trade tariffs and subsidies (equation 3) simplifies to

$$
\frac{t_{i}}{1+t_{i}}=\frac{I_{i}}{a} \cdot \frac{Z_{i}}{e_{i}}
$$


In section 4, equation (4) is adapted to the two-country case and used to rank each industry according to the relative desirability, from the point of view of the government of either Australia or the United States, of including that industry in a bilateral free trade agreement.

\subsection{Free Trade Agreements}

In the Grossman-Helpman (1995) model of free trade agreements, the GrossmanHelpman (1994) model discussed previously is treated as the first stage in the "game" of negotiating an FTA. In this first stage, the government of each country, under the influence of domestic interest groups, independently determines the schedule of trade tariffs and subsidies for that country. Then, in the second stage, the governments interact at the international level in an effort to negotiate an FTA.

Grossman and Helpman (1995) begin by describing the effects that a bilateral FTA can have on the voters and interest groups in each country. For simplicity, it is assumed that only one-way trade is possible for each good. Then, for each good, an FTA can result in "enhanced protection", "reduced protection", or an intermediate case. ${ }^{3}$ The analysis of these situations shows that exporters never lose from an FTA, and sometimes gain, while import-competing producers never gain from an FTA, and sometimes lose. This implies that in each country, interest groups representing exporters are a potential source of political support for an FTA, and interest groups representing import-competing producers are a potential source of opposition. The welfare effects on consumers can be either positive or negative.

A country will enter into an FTA only if the government supports the agreement. Grossman and Helpman (1995) assume that the objectives of the government and interest

\footnotetext{
${ }^{3}$ See Grossman and Helpman (1995, pp. 671-673).
} 
groups in each country are as in the earlier model of Grossman and Helpman (1994), so that each government is concerned with both aggregate social welfare and the sum of financial contributions received from interest groups. For the special case where only a negligible fraction of voters belongs to interest groups (as in equation 4), and, for simplicity, all industries are politically organised, Grossman and Helpman (1995) investigate the possible equilibrium outcomes of FTA negotiations. Two different types of negotiations are analysed.

The first type of negotiations requires FTAs to cover all industries, with no exceptions, so that any FTA results in completely free trade in goods between the countries involved. A government will support such an FTA only if it causes the joint welfare of the government and all interest groups in that country to increase, which can be written as:

$$
\sum_{i}\left(\Delta W_{i}-\Delta C_{i}\right)+\Delta G \geq 0
$$

This condition can be simplified by substituting $\Delta W_{i}=\Delta \pi_{i}$ for the change in welfare of the interest groups, which follows from equation (1) for the special case where $\alpha_{i}=0$; and by substituting $\Delta G=\sum_{i}\left(\Delta C_{i}+a \Delta Z_{i}\right)$ for the change in government welfare, which follows from equation (2). The term $\Delta Z_{i}$ represents the change in aggregate social welfare $W$ due to the reduction of trade barriers in industry $i$. This gives

$$
\sum_{i}\left(\Delta \pi_{i}+a \Delta Z_{i}\right) \geq 0
$$

An FTA that covers all industries can be successfully negotiated only if condition (5) holds in each country. This is most likely to occur when potential trade between the negotiating countries is relatively "balanced", meaning that in each country there must be an approximately equal number of potential exporters and import-competing producers. Then, 
the political power of interest groups representing exporters, who gain from the agreement, matches the political power of interest groups representing import-competing producers, who lose. Additionally, this type of FTA is more likely to succeed if the number of industries experiencing enhanced protection is high relative to the number experiencing reduced protection. Under enhanced protection, the gains to exporters are high and the costs to importcompeting producers are low, while under reduced protection the opposite is true. Therefore, if most industries experience enhanced protection, the gains to exporters are likely to outweigh the government's valuation of the overall costs. ${ }^{4}$

\section{Industry Exclusions}

The second type of FTA negotiations allows for a small number of industries to be excluded from the agreement. Many FTAs take this form, including the Australia-United States FTA. According to the rules of the World Trade Organization, industry exclusions are permitted as long as an FTA still removes trade barriers on "substantially all" trade in goods between the countries involved (WTO, 2005), although the precise meaning of "substantially all" is not made explicit. Grossman and Helpman (1995) show that when industry exclusions are permitted, FTA negotiations are more likely to succeed. This is because excluding certain industries can allow countries to negotiate a "balanced" agreement, even if total potential trade between those countries is relatively unbalanced.

If industry exclusions are permitted, then a government will support an FTA as long as it increases the joint welfare of the government and those interest groups representing industries that are included in the agreement. This can be written as

\footnotetext{
${ }^{4}$ Enhanced protection is a situation of trade diversion, so this also implies that FTAs tend to be successful when trade diversion prevails.
} 


$$
\sum_{i \notin \varepsilon(T)}\left(\Delta \pi_{i}+a \Delta Z_{i}\right) \geq 0
$$

where $\varepsilon(T)$ is the set of excluded industries and $T$ represents an exogenous constraint on this set, in accordance with WTO regulations. For simplicity, this constraint is assumed to be a limit on the number of industries that may be excluded. ${ }^{5}$ Note that depending on the choice of $\varepsilon(T)$, a proposed FTA may satisfy condition (6) but not condition (5).

Let $g_{i}=\Delta \pi_{i}+a \Delta Z_{i}$. Then each government would like to have all industries with $g_{i}>0$ (for that country) included in the agreement, and all industries with $g_{i}<0$ excluded, since the inclusion of an industry with $g_{i}<0$ would reduce the joint welfare of the government and the interest group representing that industry. If there is a constraint $T$ on the set of exclusions, then each government seeks to exclude the industries with the most negative values of $g_{i}$. This set of desired exclusions is generally different for each country, and, as a consequence, negotiations for this type of FTA tend to involve extensive bargaining. Grossman and Helpman (1995) use the concept of a Nash bargaining solution to analyse the equilibrium outcome of this bargaining process for the two-country case. It is shown that if an equilibrium agreement exists, it excludes those industries whose inclusion would have the largest negative effect on a geometric weighted average of the overall net gains to the two governments.

This result can be written as follows. For each industry $i$, consider the sum

$$
\omega^{A} g_{i}^{A}+\omega^{B} g_{i}^{B}
$$

where $\omega^{J}$ is an overall weighting given to the net gains of each government during negotiations, and the two countries are denoted $J=A, B$. For each government, $\omega^{J}$ depends

\footnotetext{
${ }^{5}$ Another possibility is a limit on the fraction of trade within the FTA that may be excluded.
} 
on two factors. Firstly, it increases with the Nash weight associated with that government, where the Nash weight is an exogenous measure of bargaining strength. Secondly, it decreases with the size of the total net gains of that government, since a government with large gains at stake will be more willing to compromise in order to reach an agreement.

The equilibrium agreement excludes all industries with a value of expression (7) below some critical value, which depends on the constraint $T$. In the case where $T$ is simply a limit on the number of industries that may be excluded, the equilibrium agreement excludes the $T$ industries with the largest negative values of (7). These are the industries for which the weighted sum of the gains to the exporting country's government and the losses to the importing country's government (due to the inclusion of that industry) are most negative.

If the weightings $\omega^{J}$ are approximately equal for the two countries, then industries that would experience reduced protection under the agreement are most likely to be excluded, and industries that would experience enhanced protection are least likely to be excluded. This is because for industries that would experience reduced protection, the potential gains to the exporting country are small and the losses of producers in the importing country are large, making expression (7) negative if the weightings are equal. By contrast, for industries that would experience enhanced protection, the potential gains to exporters are large and the losses in the importing country are small, so (7) is positive if the weightings are equal. In the intermediate case between enhanced and reduced protection, expression (7) may be either positive or negative, depending on the relative sizes of the gains to the exporting country and the losses to the importing country.

However, the weightings $\omega^{J}$ need not be equal. If one country has a relatively high exogenous bargaining strength, or if the agreement provides the country with only relatively small potential net gains, then $\omega^{J}$ is higher for that country. A higher $\omega^{J}$ means that the 
country's wishes are weighted more heavily during negotiations, so some industries may be excluded even if their inclusion would deliver large gains to the other country. An extreme case occurs when $\omega^{J}$ equals zero for one country, which implies that the set of exclusions is determined entirely by the other country. It may also be possible for $\omega^{J}$ to be negative for one country, in which case the set of exclusions consists of the industries that this country would most like to have included in the agreement.

\section{Empirical Methodology and Data}

\subsection{Empirical Methodology}

The aim of this paper is to test whether the model of Grossman and Helpman (1995) can predict the set of industry exclusions for the Australia-United States FTA. The empirical methodology used to conduct this test follows Gawande, Sanguinetti, and Bohara (2001). The central idea underlying this methodology is to establish a link between the GrossmanHelpman (1995) model of FTA negotiations (see section 3.2), and the Grossman-Helpman (1994) model of a single country's equilibrium trade policies (see section 3.1).

In the Grossman-Helpman (1995) model, an equilibrium FTA excludes the $T$ industries with the largest negative values of expression (7), where $T$ is an exogenous constraint on the number of exclusions. Therefore, to test whether the exclusions of the Australia-United States FTA are correctly predicted, industries must be ranked according to expression (7). This requires, for each country, a ranking of industries by $g_{i}$, which is the change in the joint welfare of the government and the interest group representing industry $i$, caused by the inclusion of industry $i$ in the agreement. 
Gawande, Sanguinetti, and Bohara (2001) show that such a ranking can be generated by a modified form of equation (4), the Grossman-Helpman (1994) solution for the size of the equilibrium import tariff or export subsidy in each industry before the FTA is negotiated (for the special case where $\alpha_{L}=0$ ). Intuitively, equation (4) implies that a pre-FTA equilibrium import tariff exists in some import-competing industry if the reduction of imports in that industry (through the imposition of the tariff) increases the joint welfare of the government and the interest group representing the industry. Hence, this joint welfare will fall if import restrictions are reduced by an FTA. Similarly, a pre-FTA export subsidy exists in an export industry if the expansion of exports (through the subsidy) increases the joint welfare of the government and the interest group representing the industry, and hence this joint welfare will rise further if exports are expanded through an FTA.

The ranking is created as follows. Define the index $(I \times z / e)_{M i}^{J}=I_{i}^{J} \times z_{i}^{J} / e_{i}^{J}$ for importcompeting industries in country $J$, and $(I \times Z / e)_{X i}^{J}=I_{i}^{J} \times z_{i}^{J} / e_{i}^{J}$ for export industries. As in equation (4), $I_{i}^{J}$ is an indicator variable that equals one if industry $i$ is politically organised (in country $J$ ) and zero otherwise, and $e_{i}^{J}$ is the import demand elasticity (positive) or export supply elasticity (negative). However, $z_{i}^{J}$ is now defined as the ratio of domestic output to bilateral imports (positive) or bilateral exports (negative). Previously, in equation (4), $z_{i}^{J}$ was defined as the ratio of domestic output to total imports or exports. This change is made because an FTA seeks to reduce barriers to bilateral trade only.

For import-competing industries, a ranking by $(I \times \mathrm{z} / e)_{M i}^{J}$ is equivalent to a ranking by $g_{i}^{J}$. This is because, firstly, the index $(I \times z / e)_{M i}^{J}$ varies positively with the size of the equilibrium tariff on bilateral imports (which can be seen from equation 4). Secondly, the size of the equilibrium tariff varies negatively with the change in the joint welfare of the 
government and the interest group representing industry $i$, caused by a tariff reduction of a given magnitude. Then, since a tariff reduction on bilateral imports of good $i$ has the same effect on trade flows as the inclusion of industry $i$ in a bilateral FTA, the size of the equilibrium tariff also varies negatively with $g_{i}^{J}$. Putting this together, it is found that $(I \times z / e)_{M i}^{J}$ varies negatively with $g_{i}^{J}$, and therefore, a ranking of import-competing industries by $(I \times \mathrm{z} / e)_{M i}^{J}$ is equivalent to a ranking by $g_{i}^{J}$ (although the ordering is reversed).

Similarly, for export industries, a ranking by $(I \times z / e)_{X i}^{J}$ is equivalent to a ranking by $g_{i}^{J}$. However, the ordering of this ranking is not reversed. The index $(I \times Z / e)_{X i}^{J}$ varies positively with the size of the equilibrium subsidy on bilateral exports (see equation 4), and since a subsidy on bilateral exports has the same effect on trade flows as the inclusion of the industry in a bilateral FTA, the index $(I \times z / e)_{X i}^{J}$ also varies positively with $g_{i}^{J}$.

When the (reversed) ranking of import-competing industries by $(I \times z / e)_{M i}^{J}$ is added to the ranking of export industries by $(I \times z / e)_{X i}^{J}$, a ranking of all industries is produced, which is identical to a ranking by $g_{i}^{J}$. An industry's position within this ranking reveals the relative desirability, from the point of view of the government of country $J$, of including that industry in a bilateral FTA. During negotiations for such an FTA, the wishes of each country are given some weighting (corresponding to $\omega^{J}$ in expression 7), and a combined ranking is established for the two countries. The equilibrium set of excluded industries then consists of the $T$ industries that are lowest on this combined ranking. This is equivalent to the GrossmanHelpman (1995) prediction that the set of excluded industries consists of the $T$ industries with the largest negative values of expression (7). 
Since the indexes $(I \times z / e)_{M i}^{J}$ and $(I \times z / e)_{X i}^{J}$ are constructed from observable variables, this combined ranking of industries can be calculated for any two countries, given values of the weightings $\omega^{J}$. This allows the following econometric specification (from Gawande, Sanguinetti, and Bohara, 2001) to be used to test whether the Grossman-Helpman (1995) model can predict the set of industry exclusions for the Australia-United States FTA.

$$
y_{i}=\beta_{0}+\beta_{1}(I \times z / e)_{M i}^{A u s}+\beta_{2}(I \times z / e)_{X i}^{A u s}+\beta_{3}(I \times z / e)_{M i}^{U S}+\beta_{4}(I \times z / e)_{X i}^{U S}+\varepsilon_{i}
$$

The dependent variable, $y_{i}$, is a binary indicator variable that equals one if industry $i$ is excluded from the FTA, and zero if it is included. The coefficients $\beta_{1}$ and $\beta_{2}$ are country weights for Australia, while $\beta_{3}$ and $\beta_{4}$ are country weights for the United States. These weights are similar to $\omega^{J}$ in expression (7), but are allowed to vary between the import and export sectors. As in expression (7), the weights for each country depend positively on the government's exogenous bargaining strength, and negatively on the size of the total net gains to the government.

The two countries are said to be "symmetric" if bargaining strengths and total net gains from the agreement are each approximately equal. In this symmetric case, the theory predicts that the estimated coefficients for the two import variables will be non-negative $\left(\beta_{1} \geq 0, \beta_{3} \geq 0\right)$ and the estimated coefficients for the two export variables will be non-positive ( $\beta_{2} \leq 0, \beta_{4} \leq 0$ ); and that there will be no significant differences in magnitude between the estimates of $\beta_{1}$ and $\beta_{3}$ or between the estimates of $\beta_{2}$ and $\beta_{4}$.

If the estimated coefficients do not follow these patterns, then the countries are not symmetric. This would imply that one of the two countries was able to secure relatively more of the industry exclusions that it sought. For example, if one of the four coefficients is found 
to equal zero, then the FTA does not contain the exclusions that were desired by the interest groups in the import or export sector that corresponds to that coefficient. In the extreme case, if one of the coefficients has the wrong sign and is statistically significant, the set of exclusions consists of industries that the interest groups in the corresponding sector would least like to have excluded.

One possible outcome is that both coefficients for one country are found to equal zero. This would mean that the set of exclusions does not conform to the wishes of interest groups in either the import sector or the export sector of that country, which could occur if the government of that country had no bargaining power during negotiations. Another possible outcome is that all coefficients have the predicted signs, but the coefficients for one country are larger in magnitude than the coefficients for the other country. This would imply that the wishes of interest groups in all four sectors were given positive weightings during negotiations, but these weightings were larger for one country. This could occur as a result of either greater bargaining power or lower total net gains in that country.

\subsection{Data Sources}

The empirical analysis on equation (8) is conducted at the six-digit level of the 1996 "Harmonized System" (henceforth 1996 HS) of product classification, developed by the World Customs Organization. At this level of disaggregation, the 1996 HS comprises approximately 5,000 categories of goods produced by manufacturing industries. The empirical analysis requires a substantial data set, which is collected from a number of 
different sources. ${ }^{6}$ For 2,675 of the six-digit categories in the 1996 HS, data are available for all required variables. Thus, the data set consists of 2,675 data points for each variable.

The dependent variable in equation (8), $y_{i}$, is a binary indicator variable that equals one if industry $i$ is excluded from the Australia-United States FTA, and zero otherwise. This variable is constructed from the official tariff schedules of the two countries under the agreement, which were obtained from the Australian government (Department of Foreign Affairs and Trade, Australia, 2005). The tariff schedules show that for most goods, import tariffs were either removed completely and immediately by both countries (effective 1 January 2005, when the FTA came into force), or pre-FTA trade was already tariff-free and hence no change was required. Some goods were (or still are) subject to transition periods of varying lengths, during which tariffs in one or both countries were progressively reduced to zero. For a small additional group of goods, existing pre-FTA tariffs were left unchanged. The variable $y_{i}$ is constructed by classifying a product category as "excluded" if, for any good within that category, import tariffs or quotas are scheduled to remain in force for at least seven years, in either country, following the introduction of the FTA. This includes all product categories containing goods that are completely excluded from the agreement, and some categories containing goods subject to extended transition periods. The original data are classified according to the 2002 revision of the HS, so the resulting data series is also converted to the 1996 HS.

The data for $y_{i}$ reveal that, of the 2,675 product categories in the data set, 458 (17.1\%) are excluded from the agreement by Australia, and 524 (19.6\%) by the United States. Most excluded categories are simultaneously excluded by both countries, and in total, 566 (21.2\%)

\footnotetext{
${ }^{6}$ See Weber (2005) for more detail on data sources and the resulting data set.
} 
are excluded by one or both countries. The set of exclusions consists mostly of agricultural industries, food/beverages/tobacco industries, and textiles/clothing/footwear industries.

The indicator variable for political organisation in Australia, $I_{i}^{\text {Aus }}$, equals one if industry $i$ is represented by a special interest group that makes financial contributions to the Australian government in order to influence trade policy, and zero otherwise. This variable is difficult to measure, so it is constructed using the indirect method of McCalman (2004), which avoids the need for direct measurement by making use of historical information on the operation of Australian trade policy. In 1960, Australia abolished a comprehensive system of import quotas and replaced these with tariffs. However, replacement tariffs were generally introduced only in industries which were the subject of investigative reports by an independent advisory body known as the Tariff Board, and these reports were almost always prepared at the request of industry lobby groups. Therefore, in the years following 1960, the Tariff Board prepared reports for almost all politically organised industries in Australia, and only very few unorganised industries. This makes it possible to identify industries that were politically organised at that time.

More recent data on the political organisation of industries in Australia are unavailable, so $I_{i}^{\text {Aus }}$ is constructed by defining an industry as politically organised if a Tariff Board report was prepared for that industry between 1960 and 1973. The year 1973 marks the last year before the Tariff Board was replaced by a newer institution. A list of all Tariff Board reports prepared during this time, classified by industry, is available in Industries Assistance Commission (1974). These reports are classified at the four-digit level of the Australian Standard Industrial Classification (ASIC) system, which contains 173 manufacturing industry classes. A direct conversion table to six-digit 1996 HS product categories does not exist, so the data series is first converted to the four-digit level of the newer Australian and New 
Zealand Standard Industrial Classification (ANZSIC) system, and then to the four-digit level of the second revision International Standard Industrial Classification (ISIC Rev 2) system. To minimise the loss of information during these conversions, the value of the indicator variable is averaged in cases where several ASIC classes correspond to one ANZSIC class, or several ANZSIC classes correspond to one ISIC Rev 2 group. Then, using a conversion table from the World Bank's Trade and Production database (Nicita and Olarreaga, 2001), the data series is converted from four-digit ISIC Rev 2 to the six-digit level of the 1996 HS.

The political organisation variable for the United States, $I_{i}^{U S}$, is taken from Goldberg and Maggi (1999), who construct this variable directly from data on campaign contributions made by individual firms during the 1981-1982 United States congressional elections. An industry group is defined as politically organised if total campaign contributions by firms within that industry group are greater than some threshold. Industries are classified according to the three-digit level of the 1972 United States Standard Industrial Classification (SIC) system, which contains 143 manufacturing industry groups. For the empirical analysis in this paper, the data series is first converted to the three-digit level of the 1987 SIC, and then to the six-digit level of the 1996 HS. The conversion from 1972 SIC to 1987 SIC is done using a concordance table by Bartelsman, Becker, and Gray (2000), and the conversion from three-digit 1987 SIC to six-digit 1996 HS is done using a table from a database maintained by Haveman (2005).

The variable $z_{i}^{J}$ is defined, for industry $i$ in country $J$, as the ratio of domestic output to bilateral imports from the FTA partner (positive) or bilateral exports to the FTA partner (negative). For Australia, output data are obtained from the Australian Bureau of Statistics (ABS, 2002), and consist of "industry gross output" figures for the year ending 30 June 1998. These data are converted from Australian dollars to US dollars using the average exchange 
rate for the year ending 30 June 1998, which is also obtained from the Australian Bureau of Statistics (ABS, 2005). The data are then converted from the four-digit level of the ANZSIC system to the four-digit level of ISIC Rev 2. For the United States, output data are primarily from the World Bank's Trade and Production database (Nicita and Olarreaga, 2001), and also from the Bureau of Economic Analysis (BEA, 2005). These data consist of "total output" figures for the year ending 31 December 1998, and are classified at the four-digit level of ISIC Rev 2.

The bilateral trade data for $z_{i}^{J}$ are all from the World Bank's Trade and Production database (Nicita and Olarreaga, 2001). Only import data are used, since import data are usually of a higher quality than export data. Thus, for each country, bilateral imports are measured directly and bilateral exports are measured as the value of imports reported by the partner country. The data are for the year ending 31 December 1998, and are classified according to the four-digit level of ISIC Rev 2. In the raw data, however, two-way trade is found to occur in every industry group, which conflicts with the assumption of Grossman and Helpman (1995) that only one-way trade is possible within each industrial classification. To reflect this assumption, $z_{i}^{J}$ is calculated using the value of net bilateral trade in each industry, where net bilateral trade is defined to be positive if imports outweigh exports, and negative if exports outweigh imports. In the majority of industries, net bilateral trade consists of exports by the United States and corresponding imports by Australia; relatively fewer product groups are on net exported by Australia and imported by the United States.

It should also be noted that the import regressors $(I \times Z / e)_{M i}^{J}$ are defined only for industries that experience net imports, and the export regressors $(I \times z / e)_{X i}^{J}$ are defined only for industries with net exports. To reflect this, $z_{i}^{J}$ is set equal to zero during the calculation of 
$(I \times z / e)_{M i}^{J}$ if industry $i$ (in country $J$ ) is an industry with net exports, and $z_{i}^{J}$ is set equal to zero during the calculation of $(I \times z / e)_{X i}^{J}$ if industry $i$ experiences net imports. Finally, the resulting data series for $z_{i}^{J}$ is converted from four-digit ISIC Rev 2 to six-digit $1996 \mathrm{HS}$ using a conversion table from the World Bank's Trade and Production database (Nicita and Olarreaga, 2001).

The remaining variable, $e_{i}^{J}$, is the elasticity of import demand (positive) for industries that experience net imports, and the elasticity of export supply (negative) for industries that experience net exports. The import demand elasticities in $e_{i}^{J}$ are taken from Kee, Nicita, and Olarreaga (2004), who provide estimates of these elasticities at the six-digit level of the 1996 HS, for a large sample of countries. Estimates of export supply elasticities do not exist at this level of disaggregation, so (following Gawande, Sanguinetti, and Bohara, 2001) the export supply elasticities in $e_{i}^{J}$ are set equal to negative unity.

\section{Results}

The aim of this paper is to test whether the Grossman-Helpman (1995) model, through equation (8), can predict the set of industry exclusions for the Australia-United States FTA. This test is performed using binary logistic regression, since the dependent variable in equation (8) is a binary indicator variable. In addition to the four regressors and intercept term shown in equation (8), the model also contains dummy variables for certain "sections" of the 1996 HS product classification system. The 1996 HS is composed of twenty-one such sections, each of which consists of a group of related product categories. Dummy variables are included for HS sections 1, 2, 3, 4, 11, 12, and 13. These dummy variables and the 
intercept term are all found to be highly significant, and all possible additional dummy variables for other HS sections are statistically insignificant. The inclusion of these seven dummy variables is also strongly favoured by a likelihood ratio test, by the Akaike information criterion, and by the Schwarz criterion.

\section{Model Fit}

The regression results show that the model fits the data set very well. The hypothesis that the four regressors in equation (8) are jointly equal to zero is strongly rejected by a likelihood ratio test and a Wald test (with four degrees of freedom). By most measures of model fit, the model performs well: the percentage of concordant observation pairs is 95.4, the GoodmanKruskal gamma statistic is 0.917 , Somers' D statistic is 0.913 , the area under the receiver operating characteristic curve is 0.956 , Kendall's tau-a statistic is 0.305 , and the Nagelkerke $\mathrm{R}^{2}$ is approximately 0.72. A Hosmer-Lemeshow goodness-of-fit test at a $5 \%$ significance level indicates evidence of a lack of fit in the model, but at a $1 \%$ significance level this finding is reversed.

TABLE 1. CLASSIFICATION TABLE

\begin{tabular}{|c|c|c|c|}
\hline \multirow[b]{2}{*}{ Observed } & \multicolumn{2}{|c|}{ Predicted } & \multirow{2}{*}{$\begin{array}{l}\text { Percentage } \\
\text { correct }\end{array}$} \\
\hline & $y_{i}=1$ & $y_{i}=0$ & \\
\hline$y_{i}=1$ & 472 & 94 & 83.4 \\
\hline$y_{i}=0$ & 165 & 1944 & 92.2 \\
\hline Percentage correct & 74.1 & 95.4 & 90.3 \\
\hline
\end{tabular}


The explanatory power of the model can also be demonstrated using a classification table, as shown in Table 1. This table displays frequency values and percentages describing the model's success rate in predicting the value of the dependent variable $y_{i}$. The percentages are high, which implies that the model performs well. The figures in Table 1 are calculated using a probability level of 0.60 , which means that predicted values of $y_{i}$ greater than 0.60 are classified as being equal to 1 (excluded from the FTA), and predicted values lower than 0.60 are classified as being equal to 0 (not excluded from the FTA). For a probability level of 0.50 , the results are similar.

\section{Estimates of Coefficients}

The model coefficients in equation (8) are denoted $\beta_{1}, \beta_{2}, \beta_{3}$, and $\beta_{4}$. Table 2 displays the maximum likelihood estimates of these coefficients, as well as the corresponding standard errors, Wald statistics, ${ }^{7}$ and two-tailed p-values. Note that the model contains an intercept term and seven dummy variables in addition to the parameters shown in Table 2. The expected signs of the coefficients (see section 4.1) are $\beta_{1} \geq 0, \beta_{2} \leq 0, \beta_{3} \geq 0$, and $\beta_{4} \leq 0$, if the two countries are assumed to be symmetric. Table 2 reveals that the estimates of $\beta_{1}, \beta_{2}$, and $\beta_{3}$ (the import coefficient for Australia, the export coefficient for Australia, and the import coefficient for the United States) have the predicted signs and are statistically significant, while the estimate of $\beta_{4}$ (the export coefficient for the United States) is statistically insignificant and has the wrong sign.

\footnotetext{
${ }^{7}$ The Wald statistics have a chi-squared distribution, with one degree of freedom, and are calculated as the square of the maximum likelihood estimate divided by the square of the standard error.
} 
TABLE 2. ESTIMATES OF COEFFICIENTS

\begin{tabular}{ccccc}
\hline \hline $\begin{array}{c}\text { Coefficient and } \\
\text { regressor }\end{array}$ & $\begin{array}{c}\text { Maximum } \\
\text { likelihood estimate }\end{array}$ & Standard error & Wald statistic & p-value \\
\hline$\beta_{1},(I \times z / e)_{M i}^{\text {Aus }}$ & $8.54 \times 10^{-3}$ & $1.65 \times 10^{-3}$ & 26.78 & 0.0000 \\
$\beta_{2},(I \times z / e)_{X i}^{\text {Aus }}$ & $-1.15 \times 10^{-1}$ & $4.80 \times 10^{-2}$ & 5.69 & 0.0171 \\
$\beta_{3},(I \times Z / e)_{M i}^{U S}$ & $1.49 \times 10^{-3}$ & $6.42 \times 10^{-4}$ & 5.41 & 0.0200 \\
$\beta_{4},(I \times Z / e)_{X i}^{U S}$ & $8.73 \times 10^{-7}$ & $2.64 \times 10^{-6}$ & 0.11 & 0.7410 \\
\hline
\end{tabular}

These findings can be interpreted as follows. Since the estimates of $\beta_{1}$ and $\beta_{3}$ are positive and statistically significant, interest groups representing import-competing industries, in either country, were successful at increasing the probability of having their industries excluded from the FTA. Since the estimate of $\beta_{2}$ is negative and statistically significant, interest groups representing export industries in Australia were successful at reducing the probability of exclusion for their industries. By contrast, since the estimate of $\beta_{4}$ is insignificantly different from zero, interest groups representing export industries in the United States were, on average, not able to reduce the probability of exclusion for their industries.

TABLE 3. RELATIVE MAGNITUDES OF COEFFICIENTS

\begin{tabular}{ccc}
\hline \hline Hypothesis & Wald chi-square statistic & p-value (one-tailed) \\
\hline$\beta_{1}-\beta_{3}=0$ (importers) & 15.85 & 0.0000 \\
$\beta_{2}-\beta_{4}=0$ (exporters) & 5.69 & 0.0086 \\
\hline
\end{tabular}


If the countries are symmetric, the theory also predicts that there will be no significant differences in magnitude between the estimates of $\beta_{1}$ and $\beta_{3}$, and between the estimates of $\beta_{2}$ and $\beta_{4}$. Table 3 displays the results of Wald tests (with one degree of freedom) of the hypotheses $\beta_{1}-\beta_{3}=0$ and $\beta_{2}-\beta_{4}=0$. The first hypothesis tests whether, overall, the interest groups in the import-competing sectors of the two countries had approximately equal influence over the choice of industry exclusions, and the second hypothesis tests whether, overall, the interest groups in the two countries' export sectors had approximately equal influence. Both hypotheses are strongly rejected in favour of the alternate hypotheses, which are $\beta_{1}-\beta_{3}>0$ and $\beta_{2}-\beta_{4}<0$. The result $\beta_{1}-\beta_{3}>0$ indicates that the Australian importcompeting sector had greater influence than the US import-competing sector over the choice of industries to exclude from the FTA, and $\beta_{2}-\beta_{4}<0$ implies that the Australian export sector had greater influence than the US export sector over the choice of industries not to exclude. Therefore, the set of industry exclusions largely reflects the wishes of Australian interest groups.

The results in Tables 2 and 3 suggest that it is incorrect to assume that the two countries are symmetric. As discussed in section 4.1, this could either mean that Australia had greater exogenous bargaining strength during negotiations, or that Australia received lower total net gains from the agreement. On a more fundamental level it can also be concluded that, since the estimates of the model coefficients are compatible with certain theoretical scenarios, and since there is a high degree of model fit, the Grossman-Helpman (1995) model is successful at predicting the set of industry exclusions for the Australia-United States FTA. 


\section{Robustness and Sensitivity}

The seven dummy variables included in the regression model were chosen based on the properties of the data set, and do not have any theoretical justification. Therefore, it is desirable to show that the regression results are robust to the choice of dummy variables. To accomplish this, tests were performed for an alternate model containing dummies for all but one of the "sections" of the 1996 HS (or equivalently, a model with no intercept term but with dummies for all sections). For this alternate model, the estimates and significance levels of the coefficients $\beta_{1}, \beta_{2}, \beta_{3}$, and $\beta_{4}$ are almost identical to the results obtained for the original model. The regression results are therefore robust to the inclusion of extra dummy variables. Moreover, the Akaike information criterion and the Schwarz criterion (both of which penalise additional regressors) show the alternate model to be inferior to the original model.

Another robustness test was conducted by repeating the empirical analysis using probit regression, rather than logistic (or logit) regression. Probit regression and logistic regression are both designed to be used with data sets containing categorical dependent variables, and usually the two techniques generate approximately the same results. This is indeed found to be the case for this data set. A probit regression on equation (8), with seven dummy variables included, generates results that are similar to those reported earlier for the logistic regression. In particular, the estimated signs of the model coefficients are unchanged. The statistical significance of the estimates of $\beta_{1}, \beta_{2}$, and $\beta_{3}$ is somewhat increased, but the estimate of $\beta_{4}$ remains statistically insignificant.

The sensitivity of the logistic regression results to changes in the data was investigated by making various changes to the data set, and repeating the logistic regression analysis (with seven dummy variables included, as previously). For the political organisation variables, this 
was done by re-classifying all industries as politically organised in both Australia and the United States, and using the resulting values of the regressors to repeat the empirical analysis. The results show the model fit to be poorer than for the original model, which indicates that the political organisation variables significantly improve the explaining power of the model. Furthermore, the estimates of the coefficients $\beta_{1}, \beta_{2}, \beta_{3}$, and $\beta_{4}$ are all statistically insignificant, which implies that the explaining power of the regressors is insignificant without the political organisation variables. These findings provide further support for the Grossman-Helpman (1995) model, since the political organisation variables represent a crucial component of the Grossman-Helpman framework.

For the import demand elasticity variables, the sensitivity of the results was investigated by setting all import demand elasticities equal to unity, in both Australia and the United States. This change to the data set is found to have only a relatively minor effect on the results. The estimated magnitudes and Wald statistics of the first three model coefficients ( $\beta_{1}, \beta_{2}$, and $\beta_{3}$ ) are increased, but the signs of these three coefficients are unchanged. The estimate of $\beta_{4}$ is negative instead of positive, but remains statistically insignificant. Thus, the logistic regression results are not likely to be sensitive to measurement error in the values of the import demand elasticities.

\section{Conclusion}

Using the empirical methodology of Gawande, Sanguinetti, and Bohara (2001), the Grossman-Helpman (1995) political economy model of FTA negotiations has been shown to be successful at predicting the set of industry exclusions for the Australia-United States FTA. The regression results reveal a high degree of model fit, and the estimates of the model 
coefficients are compatible with certain theoretical scenarios. This provides strong empirical support for the Grossman-Helpman (1995) model, and more generally, further adds to the evidence supporting the Grossman-Helpman approach towards modelling the influence of special interest groups over trade policy.

From the results of the empirical analysis, several inferences can also be made about the Australia-United States FTA. The estimated signs of the model coefficients indicate that in both Australia and the United States, interest groups representing import-competing industries were successful at increasing the probability of having their industries excluded from the FTA, and in Australia, interest groups representing export industries were successful at reducing the probability of exclusion for their industries. However, interest groups representing export industries in the United States were not successful at lowering the probability of exclusion for their industries. In addition, the relative magnitudes of the estimated coefficients indicate that overall, the Australian import-competing sector had greater influence than the US import-competing sector over the choice of industry exclusions, and the Australian export sector had greater influence than the US export sector over the choice of industries not to exclude.

These results suggest that Australia and the United States are not "symmetric", which implies either that Australia had greater exogenous bargaining strength during negotiations for the FTA, or that the overall gains from the agreement are smaller for Australia than for the United States. The model does not offer a preference between these two explanations, so either, or both, may be correct. However, if it is assumed that the bargaining strength of the United States was at least equal to that of Australia, then the results imply that the overall gains from the FTA are smaller for the government of Australia than for the government of the United States. This is because the government that is offered lower overall gains is more likely to abandon negotiations if it is not given the industry exclusions that it desires, which 
induces the other government to grant those exclusions more readily. As a result, as is observed for Australia, the government that achieves lower overall gains is granted a relatively larger number of industry exclusions.

One limitation of this paper is that the empirical analysis is restricted to goods produced by manufacturing industries. The data set does not contain any data for tradeable services, or for tradeable raw materials (such as those produced by the agriculture, fishing, forestry, and mining sectors). Tradeable services and raw materials constitute a significant portion of bilateral trade between Australia and the United States, so these omissions may affect the results. Another limitation is that the Grossman-Helpman (1995) model assumes that only one-way trade is possible within each industrial classification. The actual bilateral trade data for Australia and the United States show that two-way trade occurs within every industrial classification, so this assumption is violated. This is addressed by using net bilateral trade figures (instead of actual bilateral trade figures) in the empirical analysis, but this may be only an imperfect remedy. A further limitation is that the model does not directly reveal whether the Australia-United States FTA is beneficial or harmful to consumers in the two countries. Instead, the focus of the model is on the effects on interest groups, and the influence that interest groups have over the governments of the two countries. While this may be an accurate representation of the political process in modern democracies, it is often also desirable to know the precise effects of an FTA on consumers. 


\section{References}

Australian Bureau of Statistics. (2002) Manufacturing Establishments, Summary of Operations by ANZSIC Class, Australia, States and Territories, 1989-90 to 1999-2000. ABS Catalogue No. 8221.0: Manufacturing Industry, Australia. (2005) Period Average Exchange Rates - Units of Foreign Currency per Australian Dollar. Table 12, ABS Catalogue No. 5368.0: International Trade in Goods and Services, Australia.

Bartelsman, E.J., Becker, R.A., and Gray, W.B. (2000) NBER-CES Manufacturing Industry Database. National Bureau of Economic Research, and US Census Bureau Center for Economic Studies. Available online at http://www.nber.org/nberces/nbprod96.htm. [Accessed December 2005.]

Bureau of Economic Analysis, United States. (2005) Gross Domestic Product by Major Type of Product. Table 1.2.5, National Economic Accounts.

Department of Foreign Affairs and Trade, Australia. (2005) The Australia-United States Free

Trade Agreement, Annex 2-B: Tariff Elimination. Available online at http://www.dfat.gov.au. [Accessed July 2005.]

Feenstra, R.C. (2004) Advanced International Trade: Theory and Evidence. Chapter 9, pp. 300-337. Princeton University Press, Princeton.

Gawande, K. and Bandyopadhyay, U. (2000) "Is Protection for Sale? Evidence on the Grossman-Helpman Theory of Endogenous Protection." Review of Economics and Statistics, 82/1, 139-152.

Gawande, K., Sanguinetti, P., and Bohara, A. (2001) "Exclusions for Sale: Evidence on the Grossman-Helpman Model of Free Trade Agreements." Working Paper, University of New Mexico.

Goldberg, P.K. and Maggi, G. (1999) "Protection for Sale: An Empirical Investigation." American Economic Review, 89/5, 1135-1155.

Grossman, G.M. and Helpman, E. (1994) "Protection for Sale." American Economic Review, 84/4, 833-850. 
(1995) "The Politics of Free-Trade Agreements." American Economic Review, 85/4, 667-690.

Haveman, J. (2005) Industry Concordances. Online resource, available at http://www.macalester.edu/research/economics/page/haveman/trade.resources/ tradeconcordances.html. [Accessed July 2005.]

Helpman, E. (1997) "Politics and Trade Policy." In Kreps, D.M. and Wallis, K.F. (eds.) Advances in Economics and Econometrics: Theory and Applications, Vol. 1. Cambridge University Press, Cambridge, United Kingdom.

Industries Assistance Commission. (1974) Index of Tariff Board Reports, 1921-1973, Classified by Industry. Australian Government, Canberra.

Kee, H.L., Nicita, A., and Olarreaga, M. (2004) "Import Demand Elasticities and Trade Distortions." Working Paper, World Bank. Accompanying data file available online at http://www.worldbank.org. [Accessed July 2005.]

Levy, P.I. (1997) "A Political-Economic Analysis of Free-Trade Agreements." American Economic Review, 87/4, 506-519.

McCalman, P. (2004) "Protection for Sale and Trade Liberalization: an Empirical Investigation." Review of International Economics, 12/1, 81-94.

Nicita, A. and Olarreaga, M. (2001) Trade and Production Database, 1976-1999. World Bank. Available online at http://www.worldbank.org. [Accessed July 2005.]

Rodrik, D. (1995) "Political Economy of Trade Policy." In Grossman, G.M. and Rogoff, K. (eds.) Handbook of International Economics, Vol. 3. Elsevier, Amsterdam.

Weber, L.M. (2005) Special Interest Groups and the Australia-United States Free Trade Agreement. Master's Dissertation, University of Western Australia.

World Trade Organization. (2005) General Agreement on Tariffs and Trade (GATT), Part III, Article XXIV:8. Available online at http://www.wto.org. [Accessed July 2005.] 